\title{
REVIEW
}

Open Access

\section{Key issues in Rett syndrome: emotional, behavioural and autonomic dysregulation (EBAD) - a target for clinical trials}

\author{
Jatinder Singh ${ }^{1}$ and Paramala Santosh ${ }^{1,2^{*}}$
}

\begin{abstract}
Complex neurodevelopmental disorders need multi-disciplinary treatment approaches for optimal care. The clinical effectiveness of treatments is limited in patients with rare genetic syndromes with multisystem morbidity. Emotional and behavioural dysregulation is common across many neurodevelopmental disorders. It can manifest in children across multiple diagnostic groups, including those on the autism spectrum and in rare genetic syndromes such as Rett Syndrome (RTT). There is, however a remarkable scarcity in the literature on the impact of the autonomic component on emotional and behavioural regulation in these disorders, and on the longer-term outcomes on disorder burden.

$R T T$ is a debilitating and often life-threatening disorder involving multiple overlapping physiological systems. Autonomic dysregulation otherwise known as dysautonomia is a cardinal feature of RTT characterised by an imbalance between the sympathetic and parasympathetic arms of the autonomic nervous system. Unlocking the autonomic component of emotional and behavioural dysregulation would be central in reducing the impairment seen in patients with RTT. In this vein, Emotional, Behavioural and Autonomic Dysregulation (EBAD) would be a useful construct to target for treatment which could mitigate burden and improve the quality of life of patients. RTT can be considered as a congenital dysautonomia and because EBAD can give rise to impairments occurring in multiple overlapping physiological systems, understanding these physiological responses arising out of EBAD would be a critical part to consider when planning treatment strategies and improving clinical outcomes in these patients. Biometric guided pharmacological and bio-feedback therapy for the behavioural and emotional aspects of the disorder offers an attracting perspective to manage EBAD in these patients. This can also allow for the stratification of patients into clinical trials and could ultimately help streamline the patient care pathway for optimal outcomes. The objectives of this review are to emphasise the key issues relating to the management of EBAD in patients with $R T$, appraise clinical trials done in RTT from the perspective of autonomic physiology and to discuss the potential of EBAD as a target for clinical trials.
\end{abstract}

Keywords: Emotional, Behavioural and autonomic dysregulation, Rett syndrome, Autonomic dysfunction, Outcome measures, Clinical trials

\footnotetext{
* Correspondence: paramala.1.santosh@kcl.ac.uk

${ }^{1}$ Department of Child and Adolescent Psychiatry, Institute of Psychiatry,

Psychology and Neuroscience, King's College London, London, UK

${ }^{2}$ Centre for Interventional Paediatric Psychopharmacology and Rare Diseases,

South London and Maudsley NHS Foundation Trust, London, UK
}

(c) The Author(s). 2018 Open Access This article is distributed under the terms of the Creative Commons Attribution 4.0 International License (http://creativecommons.org/licenses/by/4.0/), which permits unrestricted use, distribution, and reproduction in any medium, provided you give appropriate credit to the original author(s) and the source, provide a link to the Creative Commons license, and indicate if changes were made. The Creative Commons Public Domain Dedication waiver (http://creativecommons.org/publicdomain/zero/1.0/) applies to the data made available in this article, unless otherwise stated. 


\section{Background}

The Autonomic Nervous System (ANS) can be separated into the sympathetic and parasympathetic nervous system and through multiple overlapping hierarchical networks; these systems continuously orchestrate and fine-tune numerous voluntary and involuntary bodily processes. Any abnormality of the ANS, otherwise known as dysautonomia or autonomic dysregulation, leads to a complex physiological picture. Clinically, autonomic dysregulation presents with a constellation of abnormalities in different components of the sympathetic and parasympathetic nervous system. This leads to imbalances in cardiac, enteric, motor and respiratory systems resulting in an autonomic crisis. There are several medical conditions that are due to imbalances in these systems and some of these include neuroleptic malignant syndrome, malignant hyperthermia, traumatic brain injury and autonomic dysreflexia [1].

At the genetic level, Riley-Day syndrome otherwise known as familial dysautonomia is a rare hereditary autonomic neuropathy caused in the majority of cases by a mutation in the IKBKAP/ELP1 gene [2]. This gene encodes the protein IKAP that is a crucial component for elongator genes, which are thought to be responsible for the development and maintenance of the ANS [3]. Despite this, the pathophysiology of autonomic dysregulation remains speculative. Studies on the IKBKAP/ELP1 gene pathway have indicated its role in neurological disorders such as those related to intellectual disability [4], epilepsy [5] and amyotrophic lateral sclerosis [6]. Autonomic failure can also result from other disorders such as those on the autoimmune and neurological spectrum including synucleinopathies, autonomic ganglionopathies and autonomic neuropathies, and have been described in detail elsewhere [7-10]. From a clinical perspective, autonomic dysregulation remains a diffuse entity in that it does not have a standardised and well-defined nomenclature that is widely accepted for clinical practice. So far under its umbrella, more than 30 names have been coined such as central autonomic dysfunction, paroxysmal sympathetic hyperactivity and hypothalamic-midbrain dysregulation syndrome [11].

A cardinal feature of autonomic dysregulation is the disruption of neurotransmitter signalling pathways that can lead to perturbations in the central and peripheral release of neurotransmitters. This can give rise to the manifestations seen clinically and is typically evident in Rett Syndrome (RTT) whereby brainstem immaturity [12-14] leads to underdeveloped neurotransmitter pathways such as those belonging to the serotonergic neurotransmitter system $[15,16]$. Others have shown that increased leptin levels in RTT appear to be associated with sympathetic over-activity as evidenced by a significant correlation between plasma leptin levels and the
LF/HF ratio (an index of sympatho-vagal balance) [17]. Studies in MeCP2 null mice have also implicated abnormalities in the locus ceruleus to impaired sympatho-vagal balance [18]. Further research is warranted to confirm these hypotheses.

This review will first introduce autonomic dysfunction and then describe Emotional, Behavioural and Autonomic Dysregulation (EBAD) in patients with RTT. Clinical trials done in patients will RTT will then be placed into context to provide insights that might influence the development of EBAD as a target for clinical trials.

\section{Aim}

The aim of this review is to appraise clinical trials undertaken in patients with RTT from the perspective of autonomic dysregulation.

\section{Method}

For the purposes of this review freely available biomedical databases PubMed, Cochrane and Scopus were searched. So that the search could be made more relevant, the Boolean Operator 'AND' was used to link the search terms together. The search words were 'Rett Syndrome AND Clinical Trial.' To improve the validity of this search, the following inclusion and exclusion criteria were implemented into the search strategy:

\section{Inclusion criteria}

- Articles in English language in academic journals.

- Peer reviewed articles.

- Articles available electronically.

\section{Exclusion criteria}

- Reviews, conference papers, short surveys, notes, book chapters, editorials, letters and articles in press.

- Articles not in English language.

- Articles not readily accessible electronically.

The search strategy showing the information about data sources, screening, identification of studies and the number of studies included is described in Fig. 1.

\section{Autonomic dysfunction in Rett syndrome} Neuronal vulnerability in Rett syndrome

Having an incidence of approximately 1:10,000 live births [19], RTT is a debilitating neurodevelopmental disorder predominantly observed in females. In the vast majority of cases ( 90\%), sporadic functional loss of the methyl-CpG binding protein 2 (MeCP2) gene causes RTT, with mutations in CDKL5, FOXG1, CTNNB1 and WDR45 genes [20-22] contributing to the rarer atypical 


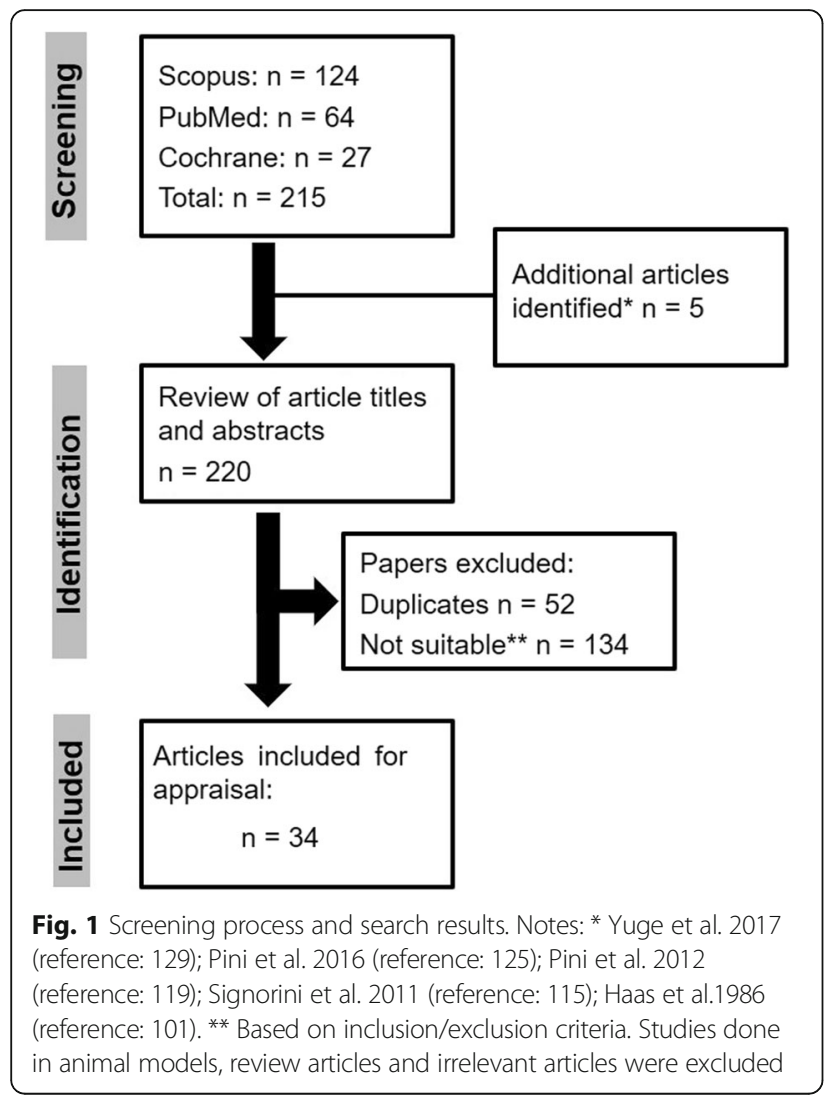

or variant RTT phenotypes. A strong evidence base points towards the MeCP2 protein being an epigenetic modulator [23-26] with pleiotropic properties binding to more than 40 structurally diverse proteins [27]. Consistent with its role as a modulator of chromatin architecture [28] more recently it was shown that the overarching function of MeCP2 was to recruit the NCoR/SMRT co-repressor complex to methylated sites on chromatin [29]. By connecting DNA to the NCoR/SMRT complex, it is likely that the $M e C P 2$ gene has far reaching genome level properties that have a critical role on the impact of genes regulating pre- and post-natal neuronal development in either the upregulation of long (>100 kb) [30] or short genes [31]. With a wide body of evidence indicating that modulation of epigenetic mechanisms associated with gene length are associated with neurodevelopment disorders [32], it underscores the premise that disruption of gene length represents a major molecular locus of vulnerability for neurons in RTT. This neuronal vulnerability can manifest as altered neurogenesis, migration and synaptic integration, and clinically can present itself as impaired developmental, motor, and social skills.

\section{Autonomic dysfunction}

The clinical phenotype of RTT is broad. Being an $\mathrm{X}$-linked gene, there are marked differences in the expression of wild-type and mutant alleles [33, 34], which has an impact on the degree of functional impairment seen in patients [35]. In terms of the degree of functional impairment, at present autonomic dysfunction appears not to be governed by a specific mutation unlike motor or cardio-respiratory phenotypes [35, 36]. Despite this, in patients with RTT the incidence of autonomic dysregulation is very high $(\sim 75 \%)$ [37] and is regarded to be a key driver of sudden death [38].

The fluidity by which MeCP2 manipulates neuronal function bestows on it a unique feature that has made the precise pathophysiology of the autonomic dysregulation seen in patients with RTT difficult to understand. Nevertheless, autonomic dysregulation has been explored in patients with RTT [17, 39-46]. One hypothesis is that unrestrained vagal tone causes a sympatho-vagal imbalance that is considered unique to patients with RTT [36]. Sympatho-vagal imbalance might contribute to about $1 / 4$ of the sudden deaths observed in females with RTT $[47,48]$, although these numbers are probably overestimated given the incomplete reporting of the cause of death in more recent studies $[49,50]$.

\section{Targeting the clinical phenotype}

The clinical phenotype of autonomic dysregulation is highly variable as individuals can exhibit broad inter-individual differences. In RTT, the autonomic dysregulation can overlap between the sympathetic, parasympathetic and enteric nervous system. Clinically, patients can present with generalised anxiety, panic attacks, breathing dysfunction, temperature dysregulation, peripheral vascular changes, enteric changes and cardiac abnormalities, and treatment often requires a personalised approach. Current strategies are largely directed towards normalising the symptoms of autonomic dysregulation in particular modifying the deleterious cardio-respiratory phenotype, which not only has a significant impact on disorder burden [51] but also seems to be the most viable clinical outcome measure for translation [52]. Targeting the serotonergic neurotransmitter system therefore appears to be a viable symptomatic strategy $[53,54]$, and presently studies are underway exploring the role of a 5-HT1A receptor agonist for the reduction of respiratory impairments in females with RTT [55]. More recently, autonomic dysregulation due to altered levels of Substance $\mathrm{P}$ expression in the brainstem of $\mathrm{MeCP} 2$ null mice was also found to be an associative factor for the respiratory deficits seen in these mice [56]; however, further work would be warranted in human studies before inferences can be made.

\section{Emotional and Behavioural dysregulation} The interplay between emotion and behaviour The ANS is the mainstay for the synergistic interplay governing human emotion and behaviour. In particular, 
the parasympathetic feedback of cardiac tissue via the vagus nerve provides a means for cardiac-respiratory output to be regulated to meet ever-changing emotional and behavioural demands [57]. Disorders in this feedback pathway and allied interconnecting networks belonging to the anterior cingulate cortex [58] and other brain regions such as the amygdala [59] are thought to be key drivers for emotional and behavioural dysregulation seen in a wide range of developmental disorders. From a developmental perspective, emotional dysregulation in childhood is associated with varied psychiatric and psychosocial deficits in adolescents [60]. Moreover, a 14-year prospective follow-up study in 2076 children showed that emotional dysregulation in childhood confers an increased risk of emotional dysregulation in early adulthood [61]. It is likely that developmental history influences the malleability of brain networks and therefore epigenetic factors associated with childhood adversity or maltreatment can have a marked impact on the developmental trajectory of behavioural and emotional brain conduits propagated into adulthood. Indeed, evidence points towards altered brain networks such as changes in the threshold of limbic reactivity in response to early childhood adversity [62] and disrupted fronto-limbic circuits as the most altered brain regions in those who have experienced childhood maltreatment [63]. These circuit changes are also consistent with the premise that these children are at higher risk of reactive aggression and autonomic hypo-responsivity $[64,65]$. Developmental traumatology is also believed to alter stress hormone responses that in turn can modify neuronal morphology in brain regions resulting in functional perturbations such as decreased right and left hemisphere integration [66]. In RTT, neuronal vulnerability and the increased electrical irritability of neural circuits produce marked changes in emotion and behaviour, and the salient points will be discussed below.

\section{Emotional and Behavioural dysregulation in RTT}

Emotional and behavioural dysregulation is frequently encountered in patients with RTT $[51,67,68]$. In RTT, the emotional state of the individual can be further exacerbated by the physical difficulties observed, for example, epileptic seizures can lead to a heightened emotional state and often leads to anxiety [69] but can also include screaming, labile mood and uncontrollable crying [67, 70]. Regarding lifespan, emotion and behaviour are thought to change during the time course of RTT [71, 72]. Behavioural dysregulation can present with increased stereotypies, repetitive rocking, scratching, self-injurious or self-stimulatory behaviour, and agitation. Some studies have indicated that emotional and behavioural impairments such as sleep problems and screaming in the early stages of RTT may be due to the occurrence of intellectual disability rather than by RTT itself $[73,74]$ and may reduce over time $[37,75]$. In RTT, evidence has shown that individuals with milder mutations are more likely to exhibit mood disturbances such as anxiety/inappropriate fear in comparison to individuals with more severe mutations who were less likely to report such difficulties [76].

While the precise cause of the emotional and behavioural dysregulation in RTT remains to be established, developmental deletion of $\mathrm{MeCP} 2$ gene in somatosensory neurons in animal models can recapitulate the core behaviour defects observed in RTT such as anxiety [77]. Recently it was also shown that MeCP2 could restrain corticotrophin releasing hormone gene expression [78], which has a key role in maintaining the homeostasis of the hypothalamic-pituitary-adrenal axis (HPA). Dysregulation of the HPA has been implicated in a variety of childhood anxiety disorders [79].

Emotional and behaviour dysregulation can have a significant impact on the quality of life in patients with RTT. Despite this, the association of autonomic dysregulation on emotional and behavioural dysregulation in RTT has not been well developed. The triumvirate consisting of (I) emotion, (II) behaviour and (III) autonomic function needs to be considered holistically in RTT and will be discussed in the next section.

\section{Emotional, Behavioural and Autonomic dysregulation in RTT}

Given the nature of the disorder, the emotional and behavioural dysregulation seen in patients with RTT has been difficult to capture. Most of the information relating to the emotional and behavioural state has been based on proxy measures such as the motor-behavioural assessment (MBA) [80], the Rett Syndrome Behavioral Questionnaire (RSBQ) [81], Anxiety Depression and Mood Scale (ADAMS) [82], the Vineland Adaptive Behaviours Scale [83], the Rett Clinical Severity Score (RCSS) [84] and the Gross Motor Scale [85]. Quality of life measures such as the Child Health Questionnaire-P50 have also been used [86]. Others have attempted to use direct observation to recognize the emotional state in patients with RTT [87, 88]; however, the outcome of the emotional and behavioural state by observers is poorly defined with no consensus on agreement by observers and underscores the need for an individualised approach.

Autonomic function together with emotional and behavioural regulation is of interest when capturing clinically meaningful change longitudinally in patients with RTT. The symptoms of EBAD and how they present clinically is shown in Fig. 2. To manage this symptomatology, biometric guided therapy can be used to map the trajectory of EBAD in patients with RTT, and in 


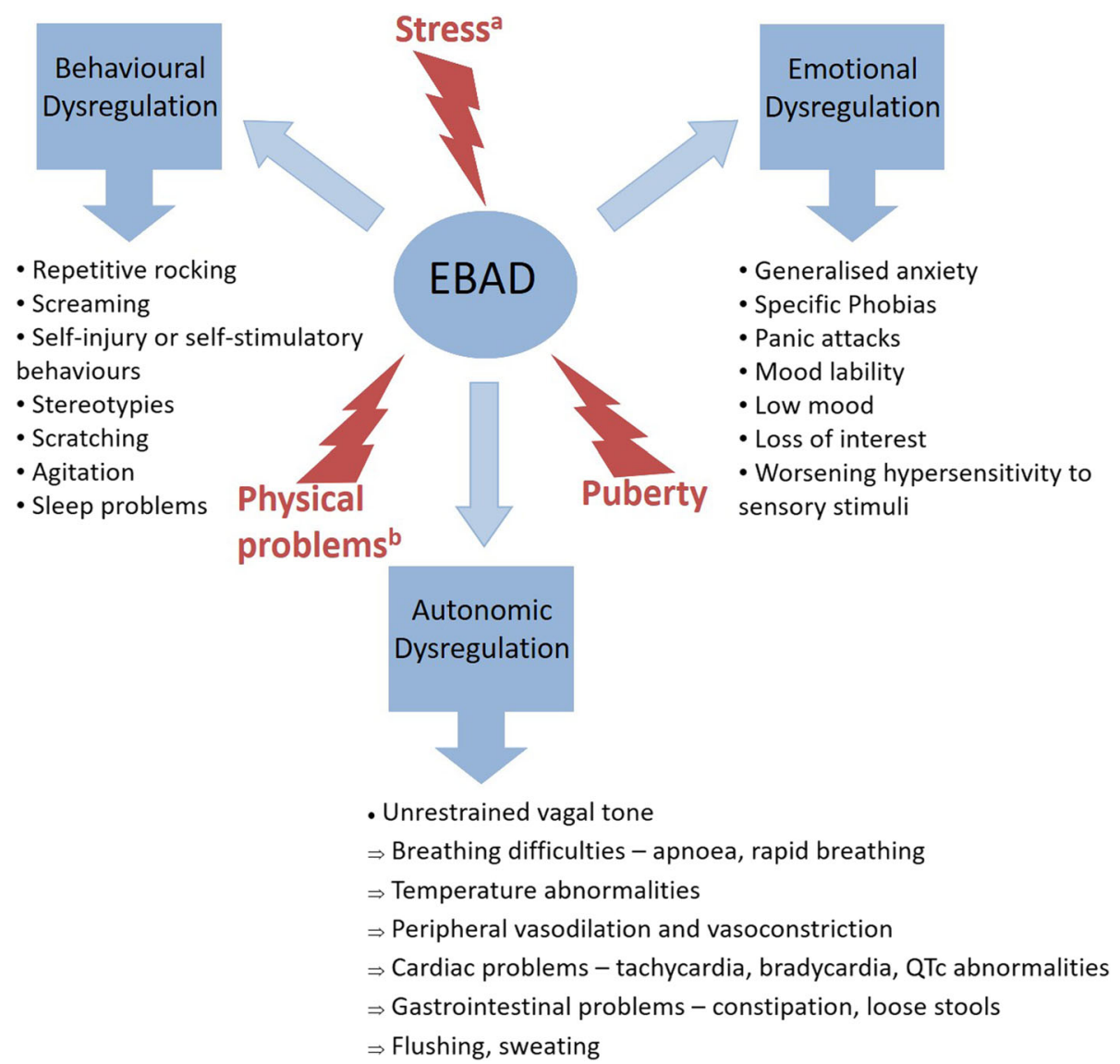

Fig. 2 Emotional, Behavioural and Autonomic Dysregulation (EBAD) and its clinical presentation in Rett Syndrome. Abbreviations: EBAD (Emotional, Behavioural and Autonomic Dysregulation). Notes: ${ }^{\text {a }}$ Stress can cause functional changes in epigenetics and it is highly probable that the epigenetic mechanisms controlled by MeCP2 form a crucial component of the stress response. ${ }^{b}$ Physical problems include seizures, pain and discomfort, and infections

those with a significant functional disability. Heart rate variability (HRV) is an indirect measure of autonomic arousal $[89,90]$ and can be measured using wearable sensor technology. Wearable sensor technology has been used as a biometric proxy measure to monitor treatment outcomes of EBAD in RTT [40, 91] and in those with other complex neurodevelopmental disorders [92]. In these cases, sensor-based biometrics can assist in the individualisation of patient care allowing the management of patients with EBAD. This strategy is currently being used in the Centre for Interventional Paediatric Psychopharmacology and Rare Diseases (CIPPRD) [93]. Further studies are warranted in other routine clinical settings.

Given that EBAD is seen in treatment non-responders with a significant functional disability frequently encountered in rare diseases and in those with complex neuropsychiatric problems, there is an urgency to provide effective treatment pathways for these patients. Despite this, there is a formal lack of guidelines on the management of EBAD in patients with RTT and highlights the need for improvements in knowledge within this area in particular regarding clinical trials. While RTT specific anchors [94] and Bayesian approaches [95] have improved outcome measures and the design of rare disease clinical trials, the ultimate goal is to harmonise interventions that can be used to monitor EBAD in RTT patients across clinical trials. Autonomic data can help in this regard and might be able to foster the development of better outcome measures for clinical trials as was shown recently in patients with breathing abnormalities [96]. Similarly, in a cohort of RTT patients, biometric data (electrodermal activity and HRV) has been used to detect an autonomic response to pain [97]. In the next section, the potential utility of EBAD as a target in clinical intervention trials will be discussed.

\section{EBAD as a target for clinical trials in RTT}

Given the clinical heterogeneity observed in patients with RTT, there is unlikely to be a 'one-size-fits-all' treatment approach. Disentangling the heterogeneity of RTT across individuals has been a real treatment challenge in terms of providing effective clinical interventions. Traditionally, 
such an approach often requires the use of 'big data' to identify patterns of interaction seen across individuals, and although big data analytics are gaining traction in psychiatry [98], such approaches are not readily feasible in RTT given the limited patient population and the difficulties in assessing patients during the life-span of the disorder. This has been exemplified in individuals with Fragile X syndrome (FXS). As a single gene disorder, FXS was thought to have had amenable drug targets, however, despite promising studies using animal models, so far, the translational potential of drug treatment for FXS has failed to live up to expectation even using well-powered double-blind placebo-controlled trials [99]. Failure of drug translatability has prompted the re-assessment of outcome measures in FXS [100] and underscores the need for more objective measures for clinical trials in RTT patients that would be able to capture clinically meaningful change longitudinally.

\section{Clinical trials in Rett syndrome}

From the search strategy (Fig. 1), 34 articles (references: [101-134]) were identified and appraised. These studies are summarised in Table 1. Details relating to the different domains of EBAD i.e., the emotional, behavioural and autonomic components have been emphasised in Table 1. Although none of the studies specifically used EBAD as a target for clinical trial intervention, a few did show promise in improving the indices of EBAD reflected in improvements in emotional, behavioural and/or autonomic dysregulation.

Autonomic dysfunction reflected by impaired cardiac output improved following treatment with omega-3 polyunsaturated fatty acids ( $\omega-3$ PUFAs). In this study, subclinical myocardial dysfunction was shown to be partially rescued in patients with RTT by high dose $\omega-3$ PUFAs supplementation for 1 year [122].

Other studies paint a complex picture. Insulin-like Growth Factor 1 (IGF-1) in its tripeptide form had no effect on cardiac vagal tone in a study of 6 RTT patients [119]; however, a later study using full length IGF-1 (also known as mecasermin) in 12 RTT patients showed improvements in breathing and peripheral autonomic function but no change in communication or motor functions [124]. An open-label study evaluating the effects of mecasermin in 10 patients also showed improvements in ISS scores [125]. The International Scoring System (ISS) is used to assess RTT severity using five separate subscales one of which considers the brainstem-autonomic component (subscale v). Despite some studies showing positive findings, a recent double-blind crossover trial assessing efficacy of mecasermin in 29 patients noted no significant improvements between treatment groups in the outcome measures tested [132]. Moreover, in that study a secondary analysis of subjects not in the placebo arm showed a worsening of symptoms.

Improvements in gait velocity and breath holding [127] were observed in patients administered glatiramer acetate (GA). On the contrary, a similarly designed study using GA was prematurely terminated due to serious adverse events (SAE) in four patients [128]. The onset of these SAEs followed administration of GA and the subsequent immediate post-injection reaction was deemed to be related to primary autonomic dysfunction [128].

Ghrelin has an important role in maintaining the balance of the parasympathetic and sympathetic nervous system [135]. In a recent pilot study, two patients with RTT showed improvements in dystonia, tremor and vasomotor reflexes following treatment with ghrelin [129]. It is possible that these improvements in clinical symptoms may be due to the ghrelin dampening down the hypertonic state of the sympathetic arm of the nervous system; however, further work would be needed in a larger sample size and randomised controls to confirm this finding.

Using a variety of outcome measures, improvements were noted in the core clinical features following dextromethorphan [130] and high dose trofinetide (IGF-1 tripeptide analogue) [131] treatment in RTT patients. Interestingly, in these studies not all parameters that were evaluated demonstrated improvements. No changes in either global severity [130] or the apnoea index [131] were noted in comparison to placebo. This was shown in a study of desipramine in 26 patients with RTT whereby no significant differences were found between treatment groups for apnoea-hypopnea index and severity [134].

The apparent contradictory findings in some of the studies previously described raises the question to what would be considered an optimal design for clinical trials done in RTT patients where the patient population is small. Clinical heterogeneity seen in RTT patients could play a significant role and others have used alternative clinical trial designs such as the modified stepped wedge approach to manage the variability in the patient population [133]. In some cases, the design of the trials could be masking the improvements in some core features of RTT symptomatology from being revealed. Another significant problem with trials in rare diseases is the mathematical problem of increased variability arising from multiple evaluators (researchers and clinicians) because only a few subjects are available from each site participating in the trial. One strategy to deal with this could be that a central research site takes the responsibility for evaluating all the outcomes in a blinded manner, using digital health strategies or building in limited visits to the main site for critical time points when outcomes evaluation is essential. Reduction in evaluator variability 


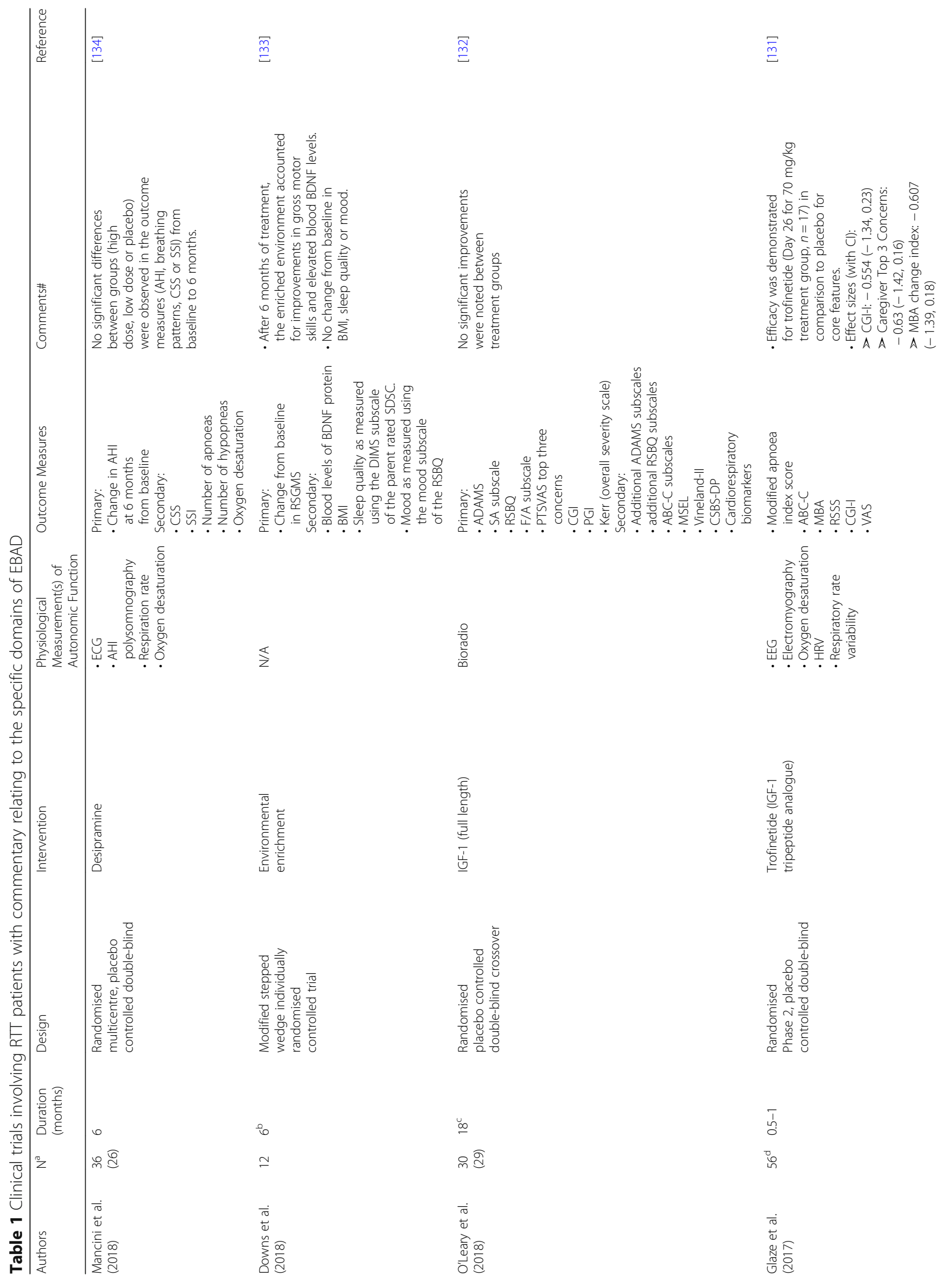




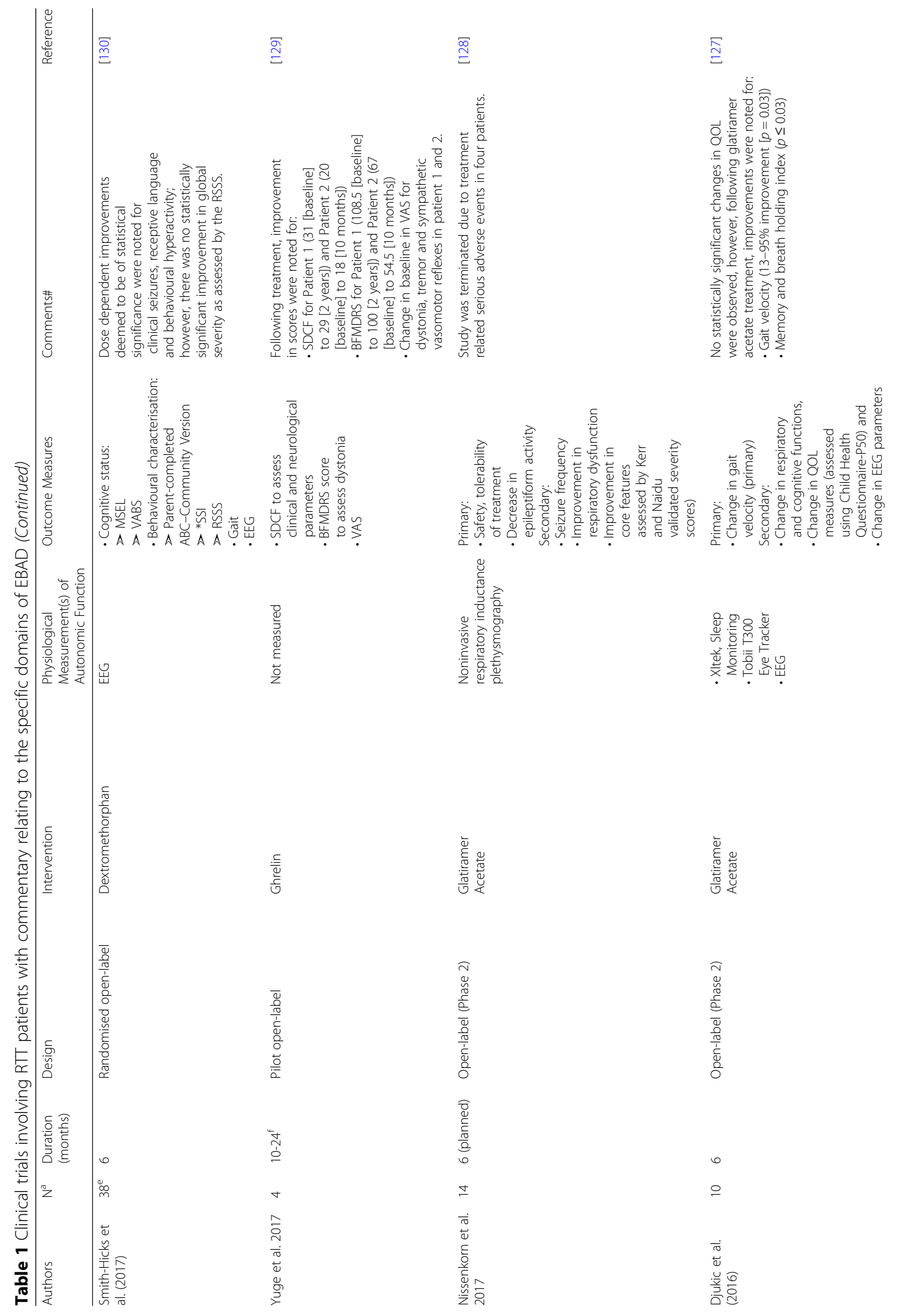


Singh and Santosh Orphanet Journal of Rare Diseases (2018) 13:128

Page 9 of 17

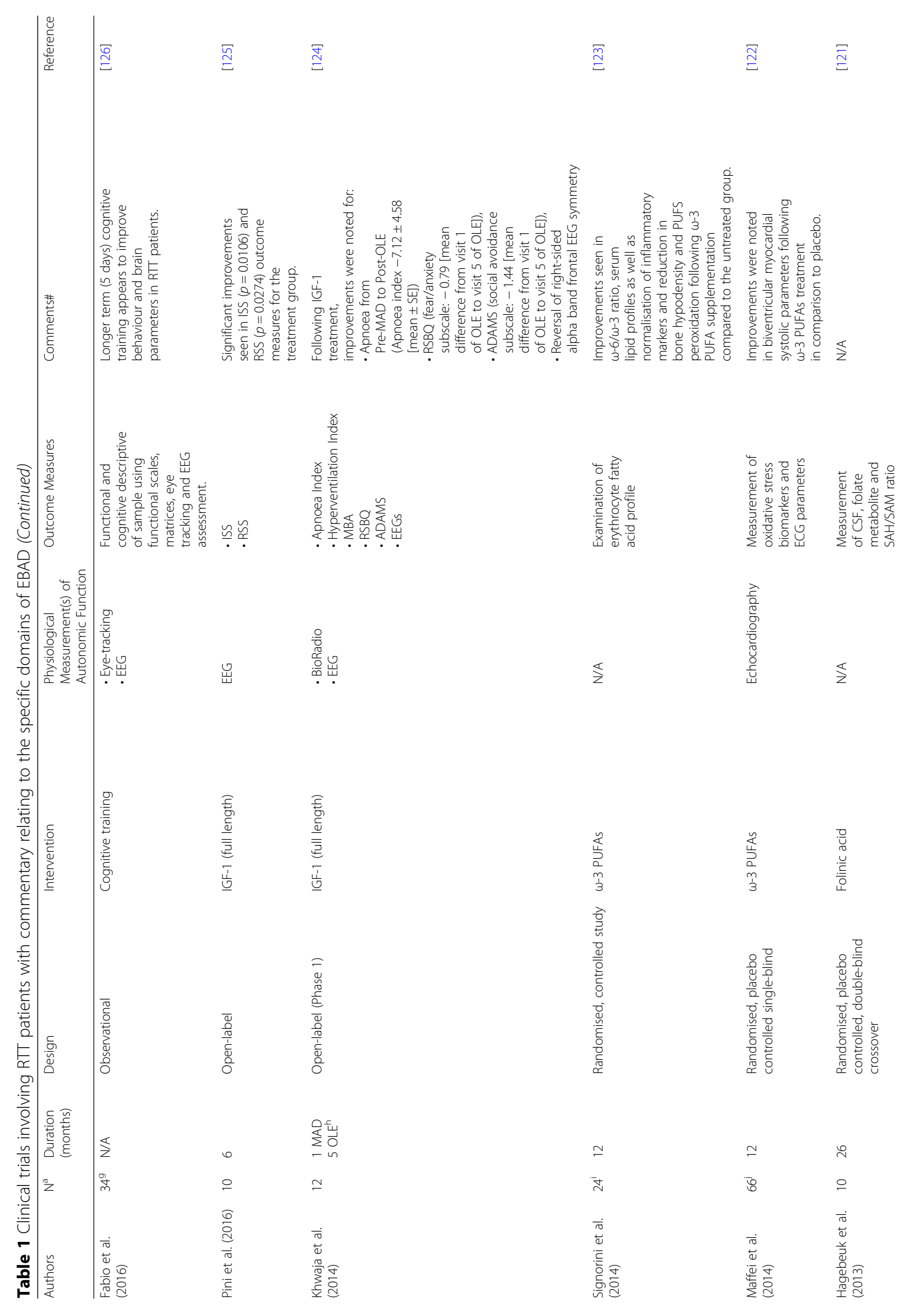




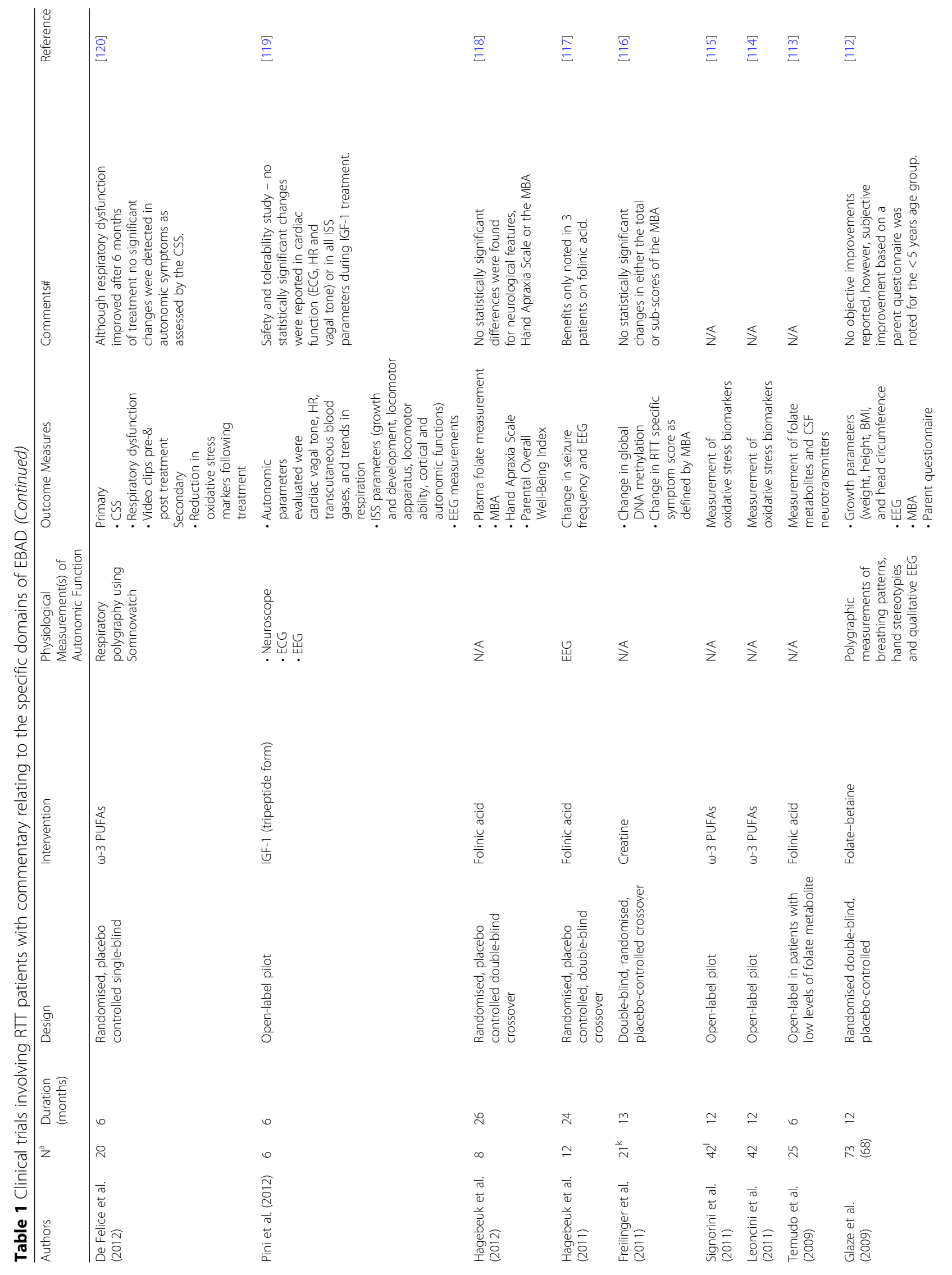




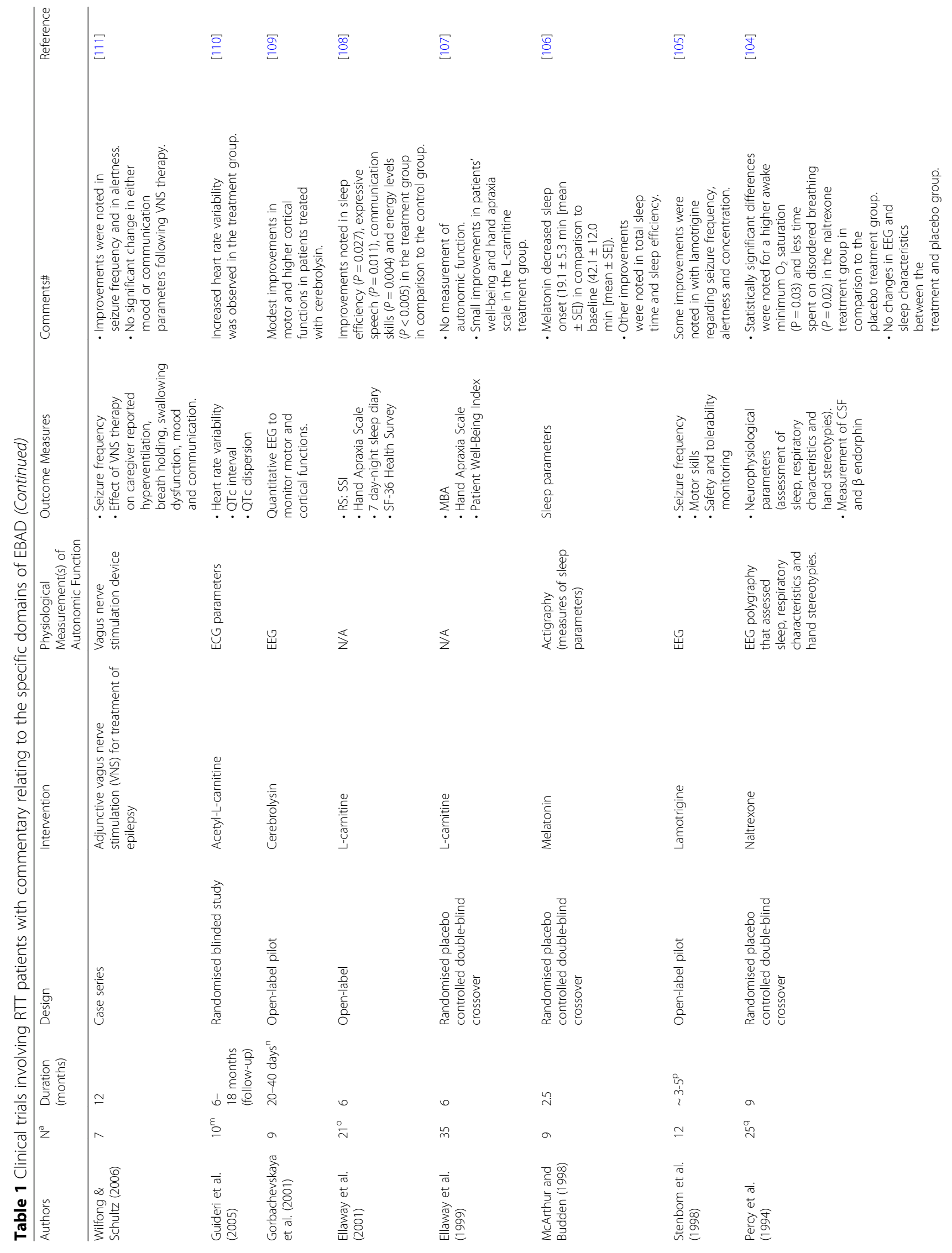




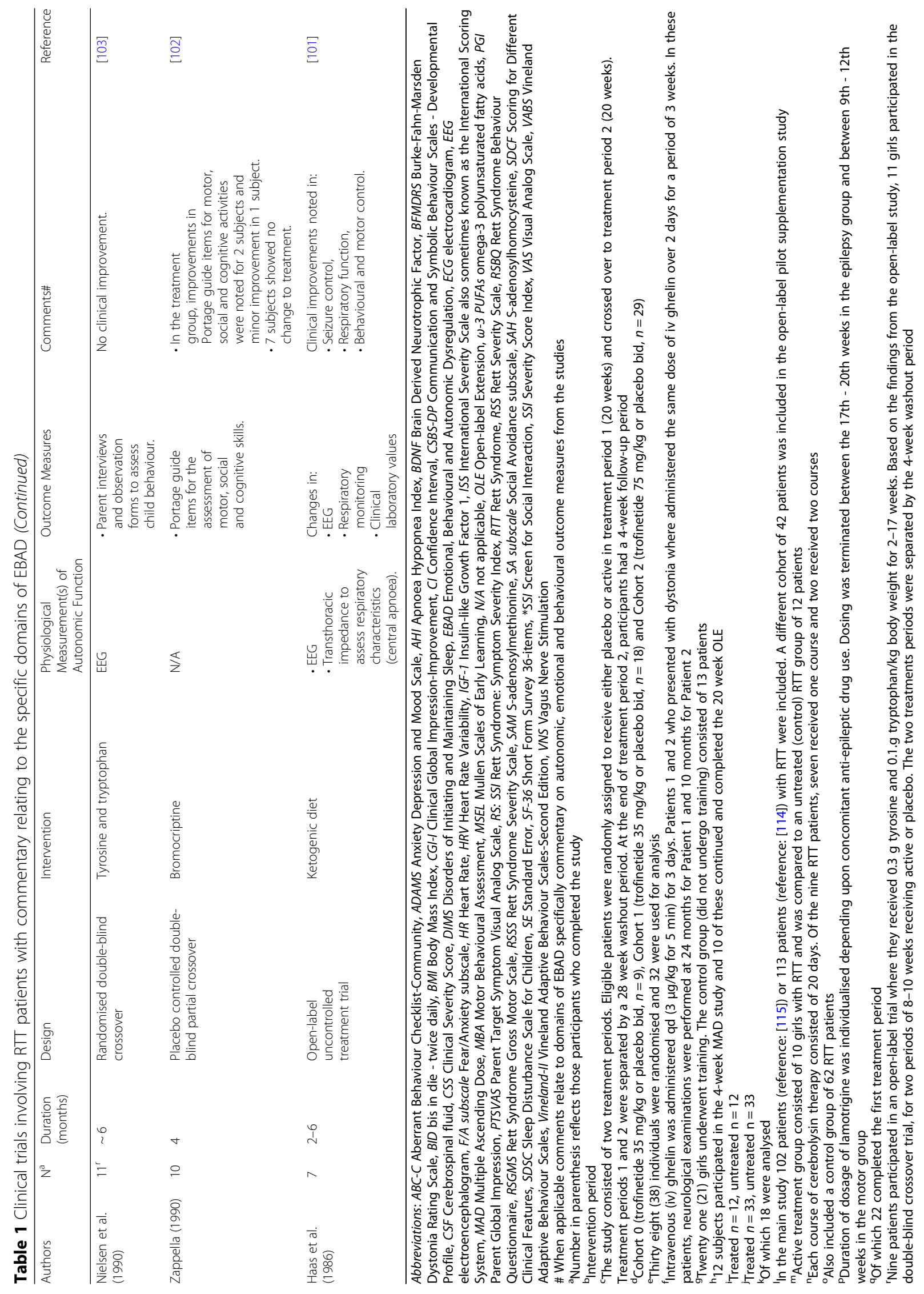


will improve the likelihood of identifying true differences between placebo and the experimental drug.

Exaggerated placebo responses can also mask the actual effect especially in the design of double-blind randomised trials. A large placebo-like response was observed in children with autism spectrum disorders, whereby caregivers reported a significant reduction in problem behaviours in the absence of treatment [136]. Moreover, one study done in RTT patients has shown a placebo effect of more than $60 \%$ [118]. Whilst wishing not to speculate on how to reduce the magnitude of the placebo effect, newer trial designs such as the two-by-two blind trial design [137] or a result dependent randomisation algorithm [138] might be adopted to mitigate such issues.

Nevertheless, these studies have paved the way for pivotal trials to be performed and have opened up other important avenues for consideration such as the use of stratification biomarkers for patients entering into clinical trials. Some progress has been made in the area, for example, the use of the frontal band asymmetry index [124] and visual evoked potentials [139] to assess anxiety/depression and brain function respectively. Biometric guided therapy that monitors the autonomic component of EBAD in RTT patients can also be used to guide the stratification of patients entering clinical trials and will be discussed in the next section.

\section{Longitudinal monitoring of EBAD across the lifespan in patients with RTT}

We have shown previously that biometric guided therapy can be used as a multimodal biomarker together with behavioural and emotional indices to manage EBAD in patients with RTT and other neurodevelopmental disorders [91, 92]. By objectively measuring the autonomic dysregulation, coupled with both observational and carer reported measures of behavioural and emotional dysregulation, EBAD could be considered as a tangible target for clinical trials. It would be useful in guiding researchers in improving inclusion criteria and hence the stratification of patients entering clinical trials. The inclusion of autonomic parameters has already led to an improved classification of patients with RTT allowing for a better prognosis [140]. Whilst this area of research in RTT is emerging, it is hoped that the development of new measures using the web-based HealthTracker $^{\text {TM }}$ health monitoring and analytics system [141] coupled with improved classification techniques [140] will boost the predictive power of stratification and allow researchers to capture clinically meaningful change of RTT symptomatology across the lifespan. Since RTT is not a homogeneous disorder but rather characterised by a nebulous developmental heterogeneity, capturing change across the lifespan would be crucial when designing stratification strategies for trials. To improve the clinical utility of such studies at least three time-points would be required so that EBAD could be tracked and have prognostic value. The longitudinal trajectory of EBAD has never been evaluated and in this view, one could have a model whereby EBAD could be tracked from childhood to adolescence where the neuro-anatomical and neuro-physiological profiles of RTT would be different. This may seem as an ambitious undertaking; however, given the multifaceted nature of RTT, new tangible outcome measures would be of benefit in terms of how we evaluate the efficacy of drugs in future clinical trials in RTT patients.

\section{Conclusions}

The take home message from this review is that clinical trials undertaken in patients with RTT have met with limited success. None of the studies so far have specifically assessed EBAD and those that have explored autonomic parameters showed a mixed profile on the efficacy of interventions. Some recent clinical trials have shown promise in ameliorating the core features in RTT with improvements in autonomic parameters. However, given the loss of $\mathrm{MeCP} 2$ capacity in fine-tuning neuronal brain development during early life and therefore triggering changes in the epigenetic states of genes potentially lasting across the life-span [142], it is very likely that single drug strategies may not be sufficient. Given the state of dysregulation of multiple overlapping physiological systems in EBAD, it is probable that there is a need for a symptom-based approach where different medications will be needed to manage different symptoms that impair subjects with RTT, thus requiring a truly personalized approach to treatment.

\section{Final remarks and the way forward}

RTT is a complex disorder and given its mutational profile; treatment has been a real clinical challenge, however, this in an exciting time for the RTT field. A concerted effort is ongoing to optimise clinical trial design and yet due to the variability in the velocity of clinical presentation, it is vital to identify unifying features in RTT so that they can be measured across clinical trials. While no outcome measure will be perfect, it would be of benefit to create better instruments for intervention studies in RTT. The development of the comprehensive web based HealthTracker ${ }^{\text {nx }}$ Rett Evaluation of Symptoms and Treatments (REST) questionnaire [141] along with objective measures such as biometric data is an important step forward in this area. These measures can be used to manage EBAD and can help to define subgroups of patients which will guide researchers to identify at baseline which group of patients might respond better to a particular treatment in the clinic or a 
drug in a clinical trial. Machine learning might also be a useful foil to consider. Recently, such an approach was used to predict motor progression in patients with Parkinson's disease thereby offering up new ways to increase the cost-effectiveness and efficiency of clinical trial design [143]. This approach is likely to have clinical value in RTT as recently machine learning was shown to be able to overcome inter-subject and inter-trial variability when classifying respiratory disturbances in patients with RTT [144]. In a rare disease population, it may also be appropriate to consider personalised strategies to measure the effectiveness of medication by using web-based systems such as the HealthTracker ${ }^{\mathrm{TM}}$ [93].

In summary, a multi-modal holistic approach is warranted to render meaningful clinical improvement in patients with RTT. The implementation of new outcome measures such as those focusing on EBAD will provide researchers with the opportunity to target a number of systems and aid in the development of better clinical trial designs.

\section{Acknowledgements}

We are grateful to Rachael Stevenson and John Sharpe from Reverse Rett (Charity Number 1136809) for providing feedback on the manuscript and Leighton McFadden (King's College London) for assisting with the literature search process.

\section{Funding}

The CIPPRD Research Team has received research funding (grant reference number: PCCTABR) from Reverse Rett (Charity Number 1136809) for ongoing research into RTT.

\section{Availability of data and materials}

Not applicable - no datasets were generated or analysed for this manuscript.

\section{Authors' contributions}

JS conducted the literature review and wrote the article. Both authors revised the draft, read and approved the final manuscript.

\section{Ethics approval and consent to participate}

Not applicable.

\section{Consent for publication}

Not applicable.

\section{Competing interests}

JS is on the professional advisory board for Reverse Rett. PS is the co-inventor of the HealthTracker ${ }^{\mathrm{TM}}$ and is the Chief Executive Officer and shareholder in HealthTracker ${ }^{\mathrm{Tm}}$

JS is a Trial Research Methodologist and PS the Principal Investigator on the Sarizotan Clinical Trial (Protocol Number Sarizotan/001/II/2015;

ClinicalTrials.gov Identifier: NCT02790034) in patients with RTT.

\section{Publisher's Note}

Springer Nature remains neutral with regard to jurisdictional claims in published maps and institutional affiliations.

Received: 5 December 2017 Accepted: 10 July 2018

Published online: 31 July 2018

\section{References}

1. Baguley IJ. The excitatory:inhibitory ratio model (EIR model): an integrative explanation of acute autonomic overactivity syndromes. Med Hypotheses. 2008;70:26-35.
2. Slaugenhaupt SA, Blumenfeld A, Gill SP, Leyne M, Mull J, et al. Tissue-specific expression of a splicing mutation in the IKBKAP gene causes familial dysautonomia. Am J Hum Genet. 2001;68(3):598-605.

3. Lefcort F, Mergy M, Ohlen SB, Ueki Y, George L. Animal and cellular models of familial dysautonomia. Clin Auton Res. 2017;27(4):235-43.

4. Addis L, Ahn JW, Dobson R, Dixit A, Ogilvie CM, et al. Microdeletions of ELP4 are associated with language impairment, autism Spectrum disorder, and mental retardation. Hum Mutat. 2015;36(9):842-50.

5. Gkampeta A, Fidani L, Clarimón J, Kalinderi K, Katopodi T, et al. Association of brain-derived neurotrophic factor (BDNF) and elongator protein complex 4 (ELP4) polymorphisms with benign epilepsy with centrotemporal spikes in a Greek population. Epilepsy Res. 2014;108(10):1734-9.

6. Simpson CL, Lemmens R, Miskiewicz K, Broom WJ, Hansen VK, et al. Variants of the elongator protein 3 (ELP3) gene are associated with motor neuron degeneration. Hum Mol Genet. 2009;18(3):472-81.

7. Stefanova N, Bucke P, Duerr S, Wenning GK. Multiple system atrophy: an update. Lancet Neurol. 2009:8:1172-8.

8. Cersosimo MG, Benarroch EE. Autonomic involvement in Parkinson's disease: pathology, pathophysiology, clinical features and possible peripheral biomarkers. J Neurol Sci. 2012;313:57-63.

9. Vernino S. Autoimmune and paraneoplastic channelopathies. Neurotherapeutics. 2012:4:305-14.

10. Muppidi S, Vernino S. Autoimmune autonomic failure. Handb Clin Neurol. 2013;117:321-7.

11. Baguley IJ, Perkes IE, Fernandez-Ortega JF, Rabinstein AA, Dolce G, Hendricks HT. Consensus Working Group. Paroxysmal sympathetic hyperactivity after acquired brain injury: consensus on conceptual definition nomenclature, and diagnostic criteria. J Neurotrauma. 2014;1;31(17):1515-20.

12. Julu PO, Witt El. Assessment of the maturity-related brainstem functions reveals the heterogeneous phenotypes and facilitates clinical management of Rett syndrome. Brain Dev. 2005;27(Suppl. 1):S43-53.

13. Julu PO, Kerr AM, Apartopoulos F, et al. Characterization of breathing and associated central autonomic dysfunction in the Rett disorder. Arch Dis Child. 2001;85:29-37.

14. Julu PO, Kerr AM, Hansen S, et al. Functional evidence of brain stem immaturity in Rett syndrome. Eur Child Adolesc Psychiatry. 1997;6(Suppl 1): 47-54.

15. Guideri F, Acampa M, Blardi $P$, et al. Cardiac dysautonomia and serotonin plasma levels in Rett syndrome. Neuropediatrics. 2004;35:36-8.

16. Paterson DS, Thompson EG, Belliveau RA, et al. Serotonin transporter abnormality in the dorsal motor nucleus of the vagus in Rett syndrome: potential implications for clinical autonomic dysfunction. J Neuropathol Exp Neurol. 2005;11:1018-27.

17. Acampa M, Guideri F, Hayek G, et al. Sympathetic overactivity and plasma leptin levels in Rett syndrome. Neurosci Lett. 2008;432:69-72.

18. Zhang X, Cui N, Wu Z, et al. Intrinsic membrane properties of locus coeruleus neurons in MECP2-null mice. Am J Physiol Cell Physiol. 2010;298:635-46.

19. Neul JL, Kaufmann WE, Glaze DG, et al. Rett syndrome: revised diagnostic criteria and nomenclature. Ann Neurol. 2010;68:944-50.

20. Evans JC, Archer HL, Colley JP, et al. Early onset seizures and Rett-like features associated with mutations in CDKL5. Eur J Hum Genet. 2005;13: 1113-20.

21. Philippe $C$, Amsallem D, Francannet $C$, et al. Phenotypic variability in Rett syndrome associated with FOXG1 mutations in females. J Med Genet. 2010; 47:59-65.

22. Percy AK, Lane J, Annese F, et al. When Rett syndrome is due to genes other than MECP2. Transl Sci Rare Dis. 2018;3(1):49-53.

23. Katz DM, Bird A, Coenraads M, et al. Rett syndrome: crossing the threshold to clinical translation. Trends Neurosci. 2017;39:100-13.

24. Shah RR, Bird AP. MeCP2 mutations: progress towards understanding and treating Rett syndrome. Genome Med. 2017;9:17.

25. Stefanelli G, Gandaglia A, Costa M, et al. Brain phosphorylation of MeCP2 at serine 164 is developmentally regulated and globally alters its chromatin association. Sci Rep. 2016:6:28295.

26. Becker A, Zhang P, Allmann L, et al. Poly(ADP-ribosyl)ation of methyl CpG binding protein 2 regulates chromatin structure. J Biol Chem. 2016;291(17):9382.

27. Lyst MJ, Bird A. Rett syndrome: a complex disorder with simple roots. Nat Rev Genet. 2015;16:261-75.

28. Della Ragione F, Vacca M, Fioriniello S, Pepe G, D'Esposito M. MECP2, a multi-talented modulator of chromatin architecture. Brief Funct Genomics. 2016;15:420-31 
29. Tillotson R, Selfridge J, Koerner MV, et al. Radically truncated MeCP2 rescues Rett syndrome-like neurological defects. Nature. 2017;550(7676):398-401.

30. Gabel HW, Kinde B, Stroud H, et al. Disruption of DNA-methylationdependent long gene repression in Rett syndrome. Nature. 2015;522:89-93.

31. Johnson BS, Zhao YT, Fasolino M, et al. Biotin tagging of MeCP2 in mice reveals contextual insights into the Rett syndrome transcriptome. Nat Med. 2017;10:1203-14.

32. Zylka MJ, Simon JM, Philpot BD. Gene length matters in neurons. Neuron. 2015;286:353-5

33. Gibson JH, Williamson SL, Arbuckle S, Christodoulou J. X chromosome inactivation patterns in brain in Rett syndrome: implications for the disease phenotype. Brain Development. 2005;27:266-70.

34. Xinhua B, Shengling J, Fuying S, Hong P, Meirong L, Wu XR. (2008). X chromosome inactivation in Rett syndrome and its correlations with MECP2 mutations and phenotype. J Child Neurol. 2008;23:22-5.

35. Leonard H, Cobb S, Downs J. Clinical and biological progress over 50 years in Rett syndrome. Nat Rev Neurol. 2017;13:37-51.

36. Halbach N, Smeets EE, Julu P, et al. Neurophysiology versus clinical genetics in Rett syndrome: a multicenter study. Am J Med Genet A. 2016:170:2301-9.

37. Sansom D, Krishnan VH, Corbett J, Kerr A. Emotional and behavioural aspects of Rett syndrome. Dev Med Child Neurol. 1993;35:340-5.

38. Guideri F, Acampa M. Sudden death and cardiac arrhythmias in Rett syndrome. Pediatr Cardiol. 2005;26:111.

39. Kumar A, Jaryal A, Gulati S, et al. Cardiovascular autonomic dysfunction in children and adolescents with Rett syndrome. Pediatr Neurol. 2017;70:61-6.

40. Santosh PJ, Bell L, Lievesley K, Singh J, Fiori F. (2016). Paradoxical physiological responses to propranolol in a Rett syndrome patient: a case report. BMC Paediatrics. 2016;29:16-194.

41. Larsson G, Julu PO, Witt El, et al. Normal reactions to orthostatic stress in Rett syndrome. Res Dev Disabil. 2013;34:1897-905.

42. Weese-Mayer DE, Lieske SP, Boothby CM, et al. Autonomic dysregulation in young girls with Rett syndrome during nighttime in-home recordings. Pediatr Pulmonol. 2008;43:1045-60.

43. Rohdin M, Fernell E, Eriksson M, et al. Disturbances in cardiorespiratory function during day and night in Rett syndrome. Pediatr Neurol. 2007;37:338-44.

44. Weese-Mayer DE, Lieske SP, Boothby CM, et al. Autonomic nervous system dysregulation: breathing and heart rate perturbation during wakefulness in young girls with Rett syndrome. Pediatr Res. 2006;60:443-9.

45. Guideri F, Acampa M, Matera MR, et al. Echocardiographic evaluation in Rett children with cardiac dysautonomia. J Pediatr Neurol. 2004;2:145-8.

46. Guideri F, Acampa M, Di Perri T, et al. Progressive cardiac dysautonomia observed in patients affected by classic Rett syndrome and not in the preserved speech variant. J Child Neurol. 2001;16:370-3.

47. Kerr AM, Armstrong DD, Prescott RJ, et al. Rett syndrome: analysis of deaths in the British survey. Eur Child Adolesc Psychiatry. 1997:6:71-4.

48. Hagberg B, Berg M, Steffenburg U. Three decades of sociomedical experiences from west Swedish Rett females 4-60 years of age. Brain and Development. 2001;23:S28-31.

49. Freilinger $M$, Bebbington A, Lanator I, et al. Survival with Rett syndrome: comparing Rett's original sample with data from the Australian Rett syndrome database. Dev Med Child Neurol. 2010;52:962-5.

50. Kirby RS, Lane JB, Childers J, et al. Longevity in Rett syndrome: analysis of the north American database. J Pediatr. 2010;156(135-138):e131.

51. Anderson A, Wong K, Jacoby $P$, et al. Twenty years of surveillance in Rett syndrome: what does this tell us? Orphanet J Rare Dis. 2014;19:9-87.

52. Katz DM, Berger-Sweeney JE, Eubanks JH, et al. Preclinical research in Rett syndrome: setting the foundation for translational success. Dis Model Mech. 2012:5:733-45.

53. Abdala AP, Bissonnette JM, Newman-Tancredi A. Pinpointing brainstem mechanisms responsible for autonomic dysfunction in Rett syndrome: therapeutic perspectives for 5-HT1A agonists. Front Physiol. 2014;30:205.

54. Abdala AP, Lioy DT, Garg SK, et al. Effect of Sarizotan, a 5-HT1a and D2-like receptor agonist, on respiration in three mouse models of Rett syndrome. Am J Respir Cell Mol Biol. 2014;50(6):1031-9.

55. https://www.clinicaltrials.gov/ct2/show/NCT02790034?term=newron\&rank=2.

56. Kida H, Takahashi T, Nakamura Y, et al. Pathogenesis of lethal aspiration pneumonia in Mecp2-null mouse model for Rett syndrome. Sci Rep. 2017; $7(1): 12032$

57. Thayer JF, Lane RD. A model of neurovisceral integration in emotion regulation and dysregulation. J Affect Disord. 2000;61(3):201-16.

58. Critchley HD. Neural mechanisms of autonomic, affective, and cognitive integration. J Comp Neurol. 2005;493(1):154-66.
59. Kober H, Barrett LF, Joseph J, et al. Functional grouping and corticalsubcortical interactions in emotion: a meta-analysis of neuroimaging studies. Neurolmage. 2008;42:998-1031.

60. McLaughlin KA, Hatzenbuehler ML, Mennin DS, Nolen-Hoeksema S. Emotion dysregulation and adolescent psychopathology: a prospective study. Behav Res Ther. 2011:49:544-54.

61. Althoff RR, Verhulst FC, Rettew DC, et al. Adult outcomes of childhood dysregulation: a 14-year follow-up study. J Am Acad Child Adolesc Psychiatry. 2010;49:1105-16.

62. Andersen SL, Lyss PJ, Dumont NL, Teicher MH. Enduring neurochemical effects of early maternal separation on limbic structures. Ann N Y Acad Sci. 1999;877:756-9.

63. Hart $H$, Rubia K. Neuroimaging of child abuse: a critical review. Front Hum Neurosci. 2012;6:1-24.

64. Shields A, Cicchetti D. Reactive aggression among maltreated children: the contributions of attention and emotion. J Clin Child Psychol. 1998; 27:381-95.

65. Ford JD, Fraleigh LA, Albert DB, Connor DF. Child abuse and autonomic nervous system hyporesponsivity among psychiatrically impaired children. Child Abuse Negl. 2010;34:507-15.

66. De Bellis MD. Developmental traumatology: the psychobiological development of maltreated children and its implications for research, treatment, and policy. Dev Psychopathol. 2001;13:539-64.

67. Cianfaglione R, Clarke A, Kerr M. A national survey of Rett syndrome: behavioural characteristics. J Neurodev Disord. 2015;7(1):11

68. Mount RH, Hastings RP, Reilly $\mathrm{S}$, et al. Behavioural and emotional features in Rett syndrome. Disabil. Rehabil. 2001;10;23(3-4):129-38.

69. Epstein A, Leonard H, Davis $\mathrm{E}$, et al. Conceptualizing a quality of life framework for girls with Rett syndrome using qualitative methods. Am J Med Genet A. 2016;170(3):645-53.

70. Barnes KV, Coughlin FR, O'Leary HM, et al. Anxiety-like behavior in Rett syndrome: characteristics and assessment by anxiety scales. J Neurodev Disord. 2015;7(1):30

71. Kaufmann WE, Tierney E, Rohde CA, et al. Social impairments in Rett syndrome: characteristics and relationship with clinical severity. J Intellect Disabil Res. 2012;56:233-47.

72. Wanzek M, Jenson WR, Houlihan D. Recognizing and treating Rett syndrome in schools. Sch Psychol Int. 2012;33:151-66.

73. Mount RH, Charman T, Hastings RP, et al. (2003) features of autism in rett syndrome and severe mental retardation. J Autism Dev Disord. 2003;33:435-42.

74. Woodyatt GC, Ozanne AE. Communication abilities in a case of Rett syndrome. J Intellect Disabil Res. 1992;36:83-92.

75. Munde V, Vlaskamp C, Ter Haar A. Social-emotional instability in individuals with Rett syndrome: parents' experiences with second stage behaviour. Intellect. Disabil. Res. 2016:60:43-53.

76. Robertson L, Hall SE, Jacoby P, et al. The association between behavior and genotype in Rett syndrome using the Australian Rett syndrome database. Am J Med Genet B Neuropsychiatr Genet. 2006;141B(2):177-83.

77. Orefice LL, Zimmerman AL, Chirila AM, et al. Peripheral Mechanosensory neuron dysfunction underlies tactile and behavioral deficits in mouse models of ASDs. Cell. 2016:166:299-313.

78. Bhave SA, Uht RM. CpG methylation and the methyl CpG binding protein 2 (MeCP2) are required for restraining corticotropin releasing hormone $(\mathrm{CRH})$ gene expression. Mol Cell Endocrinol. 2017;454:158-64.

79. Faravelli C, Lo Sauro C, Godini L, et al. Childhood stressful events, HPA axis and anxiety disorders. World J Psychiatry. 2012;2(1):13-25.

80. FitzGerald PM, Jankovic J, Percy AK. Rett syndrome and associated movement disorders. Mov Disord. 1990;5:195-202.

81. Mount RH, Charman T, Hastings RP, Reilly S, Cass H. The Rett syndrome behaviour questionnaire (RSBQ): refining the behavioural phenotype of Rett syndrome. J Child Psychol Psychiatry. 2002;43:1099-110.

82. Esbensen AJ, Rojahn J, Aman MG, Ruedrich S. Reliability and validity of an assessment instrument for anxiety, depression, and mood among individuals with mental retardation. J Autism Dev Disord. 2003:33:617-29.

83. Tarquinio DC, Hou W, Berg, et al. Longitudinal course of epilepsy in Rett syndrome and related disorders. Brain. 2017:140:306-18.

84. Neul JL, Fang P, Barrish J, et al. Specific mutations in methyl-CpG-binding protein 2 confer different severity in Rett syndrome. Neurology. 2008;70: 1313-21.

85. Downs J, Stahlhut M, Wong $\mathrm{K}$, et al. Validating the Rett syndrome gross motor scale. PLoS One. 2016;11:e0147555. 
86. Lane JB, Lee HS, Smith LW, et al. Clinical severity and quality of life in children and adolescents with Rett syndrome. Neurology. 2011;77:1812-8.

87. Bergström-Isacsson M, Lagerkvist B, Holck U, Gold C. How facial expressions in a Rett syndrome population are recognised and interpreted by those around them as conveying emotions. Res Dev Disabil. 2013;34(2):788-94

88. Woodyatt G, Marinac J, Darnell R, Sigafoos J, Halle J. Behaviour state analysis in Rett syndrome: continuous data reliability measurement. Int J Disabil Dev Educ. 2004;51(4):383-400.

89. Billman GE. Heart rate variability - a historical perspective. Front Physiol. 2011;2:86

90. Berntson GG, Bigger JT Jr, Eckberg DL, et al. Heart rate variability: origins, methods, and interpretive caveats. Psychophysiology. 1997;34:623-48.

91. Singh J, Santosh P. Psychopharmacology of Neurodevelopmental Disorders in Children, in Child and Adolescent Psychiatry: Asian Perspectives. 2017; Edition 1, Springer Nature. pp. 325-362.

92. Santosh PJ, Sagar-Ouriaghli I, Fiori F, Singh J. Using Wearable Sensor Technology to manage EBAD (Emotional, Behavioural and Autonomic Dysregulation) in patients with complex neurodevelopment disorders, Journal of Psychopharmacology. 2017; Poster B11, Abstract Supplement to Issue 31 (volume 8):A40-A41.

93. Santosh PJ, Bell L, Fiori F, Singh J. Pediatric antipsychotic use and outcomes monitoring. J Child Adolesc Psychopharmacol. 2017;27(6):546-54.

94. Neul JL, Glaze DG, Percy AK, et al. Improving treatment trial outcomes for Rett syndrome: the development of Rett-specific anchors for the clinical global impression scale. J Child Neurol. 2015;30:1743-8.

95. Hampson LV, Whitehead J, Eleftheriou D, et al. Elicitation of expert prior opinion: application to the MYPAN trial in childhood polyarteritis nodosa. PLoS One. 2015;30:10-e0120981.

96. Mackay J, Downs J, Wong K, et al. Autonomic breathing abnormalities in Rett syndrome: caregiver perspectives in an international database study. J. Neurodev. Disord. 2017:9:15

97. O'Leary HM, Marschik PB, Khwaja OS, et al. Detecting autonomic response to pain in Rett syndrome. Dev Neurorehabil. 2017;20(2):108-14.

98. Passos IC, Mwangi B, Kapczinski F. Big data analytics and machine learning: 2015 and beyond. Lancet Psychiatry. 2016;1:13-5.

99. Erickson CA, Davenport MH, Schaefer $T L$, et al. Fragile $X$ targeted pharmacotherapy: lessons learned and future directions. J Neurodev Disord. 2017;9:7.

100. Budimirovic DB, Berry-Kravis E, Erickson CA, et al. Updated report on tools to measure outcomes of clinical trials in fragile $X$ syndrome. J Neurodev Disord. 2017;9:14.

101. Haas RH, Rice MA, Trauner DA, Merritt TA. Therapeutic effects of a ketogenic diet in Rett syndrome. Am J Med Genet Suppl. 1986;1:225-46.

102. Zappella M. A double blind trial of bromocriptine in the Rett syndrome. Brain and Development. 1990;12(1):148-50.

103. Nielsen JB, Lou HC, Andresen J. Biochemical and clinical effects of tyrosine and tryptophan in the Rett syndrome. Brain and Development. 1990;12(1): $143-7$.

104. Percy AK, Glaze DG, Schultz RJ, et al. Rett syndrome: controlled study of an oral opiate antagonist, naltrexone. Ann Neurol. 1994:35(4):464-70.

105. Stenbom Y, Tonnby B, Hagberg B. Lamotrigine in Rett syndrome: treatment experience from a pilot study. Eur Child Adolesc Psychiatry. 1998:7(1):49-52.

106. McArthur AJ, Budden SS. Sleep dysfunction in Rett syndrome: a trial of exogenous melatonin treatment. Dev Med Child Neurol. 1998;40(3):186-92.

107. Ellaway C, Williams K, Leonard H, Higgins G, Wilcken B, Christodoulou J. Rett syndrome: randomized controlled trial of L-carnitine. J Child Neurol. 1999;14(3):162-7.

108. Ellaway CJ, Peat J, Williams K, Leonard H, Christodoulou J. Medium-term open label trial of L-carnitine in Rett syndrome. Brain and Development 2001;23(Suppl 1):S85-9.

109. Gorbachevskaya N, Bashina V, Gratchev V, Iznak A. Cerebrolysin therapy in Rett syndrome: clinical and EEG mapping study. Brain and Development. 2001:23(Suppl 1):S90-3.

110. Guideri F, Acampa M, Hayek Y, Zappella M. Effects of acetyl-L-carnitine on cardiac dysautonomia in Rett syndrome: prevention of sudden death? Paediatr. Cardiol. 2005;26(5):574-7.

111. Wilfong AA, Schultz RJ. Vagus nerve stimulation for treatment of epilepsy in Rett syndrome. Dev Med Child Neurol. 2006;48(8):683-6.

112. Glaze DG, Percy AK, Motil KJ, et al. A study of the treatment of Rett syndrome with folate and betaine. J Child Neurol. 2009;24(5):551-6.
113. Temudo T, Rios M, Prior C, et al. Evaluation of CSF neurotransmitters and folate in 25 patients with Rett disorder and effects of treatment. Brain and Development. 2009;31(1):46-51

114. Leoncini S, De Felice C, Signorini C, et al. Oxidative stress in Rett syndrome: natural history, genotype, and variants. Redox Rep. 2011;16(4):145-53.

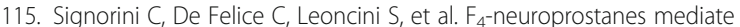
neurological severity in Rett syndrome. Clin Chim Acta. 2011;412(15-16): 1399-406.

116. Freilinger M, Dunkler D, Lanator I, et al. Effects of creatine supplementation in Rett syndrome: a randomized, placebo-controlled trial. J Dev Behav Pediatr. 2011:32(6):454-60.

117. Hagebeuk EE, Koelman JH, Duran M. Clinical and electroencephalographic effects of folinic acid treatment in Rett syndrome patients. J Child Neurol. 2011;26(6):718-23.

118. Hagebeuk EE, Duran M, Koelman JH. et al. Folinic acid supplementation in Rett syndrome patients does not influence the course of the disease: a randomized study. J. Child Neurol. 2012;27(3):304-309.

119. Pini G, Scusa MF, Congiu L. et al. IGF1 as a Potential Treatment for Rett Syndrome: Safety Assessment in Six Rett Patients. Autism Res Treat. 2012; 2012:679801.

120. De Felice C, Signorini C, Durand T, et al. Partial rescue of Rett syndrome by $\omega$-3 polyunsaturated fatty acids (PUFAs) oil. Genes Nutr. 2012;7(3):447-58.

121. Hagebeuk EE, Duran M, Abeling NG, et al. S-adenosylmethionine and S-adenosylhomocysteine in plasma and cerebrospinal fluid in Rett syndrome and the effect of folinic acid supplementation. J Inherit Metab Dis. 2013;36(6):967-72

122. Maffei $S$, De Felice $C$, Cannarile $P$, et al. Effects of $\omega-3$ PUFAs supplementation on myocardial function and oxidative stress markers in typical Rett syndrome. Mediat Inflamm. 2014;983178

123. Signorini C, De Felice C, Leoncini S, et al. Altered erythrocyte membrane fatty acid profile in typical Rett syndrome: effects of omega-3 polyunsaturated fatty acid supplementation. Prostaglandins Leukot Essent Fatty Acids. 2014;91(5):183-93.

124. Khwaja OS, Ho E, Barnes KV, et al. Safety, pharmacokinetics, and preliminary assessment of efficacy of mecasermin (recombinant human IGF-1) for the treatment of Rett syndrome. Proc Natl Acad Sci U S A. 2014;111(12):4596-601.

125. Pini G, Congiu L, Benincasa A, et al. Illness Severity, Social and Cognitive Ability, and EEG Analysis of Ten Patients with Rett Syndrome Treated with Mecasermin (Recombinant Human IGF-1). Autism Res Treat. 2016;5073078

126. Fabio RA, Billeci L, Crifaci $G$, et al. Cognitive training modifies frequency EEG bands and neuropsychological measures in Rett syndrome. Res Dev Disabil. 2016:53-54:73-85.

127. Djukic A, Holtzer R, Shinnar S, et al. Pharmacologic treatment of Rett syndrome with Glatiramer acetate. Pediatr Neurol. 2016;61:51-7.

128. Nissenkorn A, Kidon M, Ben-Zeev B. A potential life-threatening reaction to Glatiramer acetate in Rett syndrome. Pediatr Neurol. 2017;68:40-3.

129. Yuge K, Hara M, Okabe $R$, et al. Ghrelin improves dystonia and tremor in patients with Rett syndrome: a pilot study. J Neurol Sci. 2017;377:219-23.

130. Smith-Hicks CL, Gupta S, Ewen JB, et al. Randomized open-label trial of dextromethorphan in Rett syndrome. Neurology. 2017;89(16):1684-90.

131. Glaze DG, Neul JL, Percy A, et al. A double-blind, randomized, placebocontrolled clinical study of Trofinetide in the treatment of Rett syndrome. Pediatr Neurol. 2017;S0887-8994(17):30405-8.

132. O'Leary HM, Kaufmann WE, Barnes KV, et al. Placebo-controlled crossover assessment of mecasermin for the treatment of Rett syndrome. Ann Clin Transl Neurol. 2018:5(3):323-32.

133. Downs J, Rodger J, Li C, et al. Environmental enrichment intervention for Rett syndrome: an individually randomised stepped wedge trial. Orphanet J Rare Dis. 2018;13(1):3.

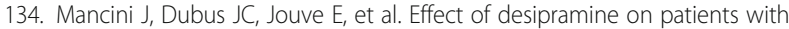
breathing disorders in RETT syndrome. Ann Clin Transl Neurol. 2017;5(2): $118-27$

135. Kojima M, Kangawa K. Ghrelin structure and function. Physiol Rev. 2005;85: 495-522.

136. Jones RM, Carberry C, Hamo A, Lord C. Placebo-like response in absence of treatment in children with autism. Autism Res. 2017:10(9):1567-72.

137. Chassang S, Snowberg E, Seymour B, Bowles C. Accounting for behavior in treatment effects: new applications for blind trials. PLoS One. 2015;10(6): e0127227.

138. Berry D. Bayesian statistics and the efficiency and ethics of clinical trials. Statistical Sci. 2004;19:175-87. 
139. LeBlanc JJ, DeGregorio G, Centofante E, et al. Visual evoked potentials detect cortical processing deficits in Rett syndrome. Ann Neurol. 2015;78(5): 775-86.

140. Pini G, Bigoni S, Congiu L, et al. Rett syndrome: a wide clinical and autonomic picture. Orphanet J. Rare Dis. 2016;11(1):132.

141. Santosh P, Lievesley K, Fiori F, Singh J. Development of the tailored Rett intervention and assessment longitudinal (TRIAL) database and the Rett evaluation of symptoms and treatments (REST) questionnaire. BMJ Open. 2017;7(6):e015342.

142. Stroud H, Su SC, Hrvatin S, et al. Early-Life Gene Expression in Neurons Modulates Lasting Epigenetic States. Cell. 2017:S0092-8674(17):31141-8.

143. Latourelle JC, Beste MT, Hadzi TC, et al. Large-scale identification of clinical and genetic predictors of motor progression in patients with newly diagnosed Parkinson's disease: a longitudinal cohort study and validation. Lancet Neurol. 2017:16(11):908-16.

144. O'Leary HM, Mayor JM, Poon C-S, et al. Classification of respiratory disturbances in Rett Syndrome patients using Restricted Boltzmann Machine. Conf Proc IEEE Eng Med Biol Soc. 2017;2017:442-5.

Ready to submit your research? Choose BMC and benefit from:

- fast, convenient online submission

- thorough peer review by experienced researchers in your field

- rapid publication on acceptance

- support for research data, including large and complex data types

- gold Open Access which fosters wider collaboration and increased citations

- maximum visibility for your research: over $100 \mathrm{M}$ website views per year

At BMC, research is always in progress.

Learn more biomedcentral.com/submissions 